acuteness of smell $=1$, the result will be $: o^{\prime}=\frac{l}{l^{\prime}} \cdot \mathrm{My}$ limited experience has furnished me with the remarkable fact that the proportion $\frac{l}{b^{\prime}}$, as a rule, is not subject to moditication, using instruments made of quite different materials (wax, balsamum tolu tanum, resina benzoës, russian leather, greasy matters, soaps, and scented woods). From this it must be concluded that in nearly every instance sensibility to different qualities of odour has equally diminished. This is why, for ordinary examination, two olfactometers are sufficient. Not so, however, when the seat of the pathological process is in the central organ. Extensive examination with several olfactometers of aifferent materials would then be required. Our analysis of the perception of odour is still so imperfect that it is not possible to follow a rational method. It is only when the velocity of diffusion is calculated that we shall be able to form a theory on odours which will guide us in this kind of examination.

I do not suppose the extensive many-sided examination last mentioned will ever become popular as a clinical method. It takes too much time, and is seldom rewarded by positive results, but I hope that the limited observation of a blunted sense of smell, as described at the beginning of this essay, as affecting all qualities alike, will be found so simple, easy, and inexpensive, that it will come into general use.

Utrecht.

\section{Clinical atetes:}

\section{MEDICAL, SURGICAL, OBSTETRICAL, AND THERAPEUTICAL。}

\section{BILIOUS VOMITING AND HEART DISEASE.}

\section{By John Grant, M.B., C.M. EdiN.}

TeERE are few practitioners who have not had to regret their inability to cope with the gastric disturbance accompanying an acute bilious attack. Per se and in the average patient, though distressing, it is not serious, and it is something to be able to tell the sufferer that, though much prostrated, he is not in a dangerous condition. Associated with some complications, it is, however, a veritable evil, and its disastrous effects have been so prominently brought before me that I think it well to give a word of warning.

A woman aged sixty-three years, the subject of oldstanding heart disease, was suffering from an attack of neuralgia, and I was asked in the evening to prescribe a sedative, to relieve the pain and procure sleep. I wrote a prescription containing chloral hydrate, bromide of ammonium, morphia, and tincture of strophanthus, to be given every two hours till relief was obtained. At 8 o'clock next morning I was summoned, and found the patient suffering from an acute bilious attack, accompanied by distressing vomiting and headache. On inquiry I found she had taken two doses of the mixture I had ordered, when the pain left her and she fell asleep, but, awaking at 5. A $M$ on the following morning, had been retching ever since. She was much prostrated, and possessed with a fear of impending death, in which her friends participated, and to which she made frequent allusion. I made a careful examination of the pulse, and found it good and regular, and hastened to reassure her and her friends that, though suffering greatly and much weakened, I did not consider her condition was a dangerous one, and added that I had never known a fatal case of bilions vomiting. I ordered sinapisms to the epigastrium and calves of the legs, and prescribed a mixture containing ten grains of subnitrate of bismuth, one minim of dilute hydrocyanic acid (B.P.), and fifteen minims of aromatic spirit of ammonia, directing the patient to be kept quiet, and prognosticating that the vomiting would probably soon cease and the patient fall asleep. About half an hour afterwards I was again urgently called, being told that the patient was dying, and, taking some digitalis and sulphuric ether mixed, I hurried to her, only to find she had just expired. She had had one dose of the bismuth mixture, and the sinapisms had been applied. I need hardly say how disappointed I was, and I take this opportunity of warning all young practitioners (of whom I am one) to be very guarded as to their prognosis in a case of this nature. If any of my older brethren will tell me of some effectual and rapid method of combating vomiting and the reflex depressant action on the heart in such cases, I shall be truly grateful.

Maidstone.

\section{CASE OF RAYNAUD'S DISEASE} By J. A. WeTHERELL, M.B.

Nicholas B-, aged fifty-eight, was received into the Barnsley Union Infirmary on March 29th, 1889, suffering from Raynaud's disease. He was on admission in $a_{\text {s }}$ state of coma-in fact, dying. Nothing of his previous history could be ascertained. On physical examination of the chest the heart sounds were inaudible, being masked by the sonorous rhonchi of the quickened respiration. The man, however, was labouring under cardiac dyspnoea. The pulse was very rapid and barely perceptible; arteries not rigid or athero. matous. The feeble circulatory power, moreover, was evinced by blueness (asphyxie locale) of the nose, which contrasted greatly with the blanching of the remainder of the face. Angemia was not marked. The gangrene was confined to the middle fingers of the hands, but differed in extent on the surfaces. The particulars are as follows: (a) Right middle finger : 1 . On the dorsum, the whole skin, except a small patch on each supero-lateral angle, is quite dead, right up to the metacarpo-phalangeal joint. Here there is a broad areola of congestion, as if the disease were spreading. 2. Palmar surface: The diseased area is restricted to the skin over the terminal phalanx. It, like that on the dorsum, is black and mortified, and possesses a large bulla filled with sanious fluid. (b) Left middle finger: 1. The dorsum is affected in its entirety. 2. The palmar surface from the tip to the proximal end of the second phalanx is gangrenous. A large ulceration on the pulp of the third penetrates to the bone, exposing it to view. The remainder of the body is normal in all respects.

The features of interest in this typical case are-(1) The age of the pasient (fifty-eight); this is somewhat of an exception to the rule. (2) The limitation of the gangrene toportions only of each middle finger-symmetry itself,-thus exhibit. ing the weakness of the neurotic theory, as accounting for all the clinical characters. (3) The absence of pallor-i.e., syncope locale-from the remaining surface of the extremities. Barnsley.

\section{TWO CASES (BROTHERS) OF ACUTE PNEUMONIA} COMPLICATED BY RETENTION OF URINE. By R. E. Johnson, L.S.A.

G. C—, aged twenty-two, was seized with a rigor at 7 P.M. on Jan. 14th, followed by acute pneumonia at the bases of both lungs. He was given a mixture containing ten minims of ipecacuanha wine, one-sixteenth of a grain of tartrate of antimony, and two minims of tincture of aconite. (In Jan. 15th there was profuse expectoration, streaked with blood, a temperature of $104^{\circ}$, and complete retention of urine. Catheterisation was employed. The pneumonis gradually subsided, but the catheter had to be passed thrice a day until Jan. 23rd, when he passed urine normally. There were slight symptoms of cystitis, but they yielded to one washing out of the bladder with a solution of carbolic acid ( 1 in 150$)$.

J. C- , aged nineteen, brother of the above. He had a rigor on Jan. 16th, followed by acute pneumonia at the base of the right lung. He also had hæmoptysis for two days. On the first day the temperature was $102^{\circ}$, and he had retention of urine on the 17 th. Catheterisation was employed thrice a day until the $22 \mathrm{nd}$, when he passed urine normally.

These cases strike me as being remarkable; both brothers suffering from pneumonia, both having hæemoptysis, and both having retention of urine, lasting in one case nine days and in the other six days. The family is peculiar; the sons (four in number) all suffer from talipes planus, as does the father. The daughters (three) and the mother are all subject to nervous disorders, the eldest daughter having had epileptiform puerperal convulsions at her first confinement; another daughter, aged twelve, has a nervous impediment in her speech; and the youngest, aged nine, suffers from petit mal.

Chester-le-Street. 